\title{
Biochemical Markers of Salt Stress in European Larch (Larix decidua)
}

\author{
Ioana M. PLESA ${ }^{1,2}$, Mohamad Al HASSAN ${ }^{2,3}$, Adriana F. SESTRAS ${ }^{1}$, \\ Oscar VICENTE2 ${ }^{2}$, Monica BOSCAIU ${ }^{4 *}$, Radu E. SESTRAS ${ }^{1}$ \\ ${ }^{1}$ University of Agricultural Sciences and Veterinary Medicine, Faculty of Horticulture, 3-5 Mănăștur Street, 400372 Cluj-Napoca, \\ Romania; ioanaplesa13@gmail.com; adriana.sestras@usamvcluj.ro; rsestras@usamvcluj.ro \\ ${ }^{2}$ Universitat Politècnica de València, Institute of Plant Molecular and Cellular Biology (IBMCP, UPV-CSIC), Camino de Vera s/n, 46022, \\ Valencia,Spain;ovicente@ibmcp.upv.es \\ ${ }^{3}$ Lebanese Canadian University (LCU), Faculty of Engineering, Department of Biotechnology, Aintoura, \\ Lebanon; mohamad_al_hassan@live.com \\ ${ }^{4}$ Universitat Politècnica de València, Spain, Mediterranean Agroforestry Institute (IAM, UPV), Camino de Vera s/n, 46022, Valencia, \\ Spain;mobosnea@eaf.upv.es (*correspondingauthor)
}

\begin{abstract}
Larix decidua, the European larch, does not grow in natural saline areas, but it can be affected by salinity either by the common practice of winter de-icing of mountain roads with $\mathrm{NaCl}$, or when grown as an ornamental tree in urban areas by the use of low quality, salinised irrigation water. In the present study, the responses to salt stress of young seedlings obtained from seeds of seven Carpathian larch populations were analysed. After 30 days of treatments with $150 \mathrm{mM} \mathrm{NaCl}$, growth and biochemical parameters were determinated. Salt stress inhibited growth of all seedlings, as shown by the relative reduction of stem length and fresh weight, and induced significant changes in the needle levels of several biochemical stress markers. Seedlings from all populations showed a marked reduction of photosynthetic pigments contents and an increase of proline and malondialdehyde (MDA) concentrations. Under salt stress, plants accumulated $\mathrm{Na}^{+}$and $\mathrm{Cl}^{-}$in the needles, whereas $\mathrm{K}^{+}$was maintained at a steady level. Responses of seedlings from the different populations were similar, with only small quantitative differences that did not allow the identification of more salt tolerant genotypes. However, the study revealed that several of the biochemical markers mentioned above can be suitable for the rapid and non-destructive assessment of the effects of salinity in European larch.
\end{abstract}

Keywords: conifer species; ions; proline; photosynthetic pigments; salinity; seedlings

\section{Introduction}

Plants, being sessile organisms, cannot respond to stressful environmental conditions by moving to more favourable places; their responses to stress are based, fundamentally, on the activation of physiological and biochemical defence mechanisms. Abiotic stresses include, among many others, soil alkalinity and acidity, too high or too low temperatures, flooding, heavy metals or UV light irradiation; however, none of them is as damaging to agricultural yields and food production as drought and soil salinity (Boyer, 1982; Bartels and Sunkar, 2005). These two stress conditions are forecasted to become more intense and frequent in the coming decades due to the effects of climate change, including higher average temperatures, reduced rainfall and increasing scarcity of water for irrigation (Koskela et al., 2007; Lindner et al., 2010; Várallyay, 2010).
Soil salinisation induces both osmotic and ionic stress in the affected plants, leading to reduced photosynthesis and inhibition of growth. This is followed by the onset of oxidative stress, causing damage to different cellular components, such as membranes, proteins and nucleic acids (Zhu, 2016). All plant species activate the same general mechanisms as a response to salt stress - based, for example, in the control of ion transport, the maintenance of cellular osmotic equilibrium or the activation of antioxidant systems (Apel and Hirt, 2004; Bartels and Sunkar, 2005; Munns and Tester, 2008). However, the efficiency of these responses varies widely between species, in a continuous range from extremely sensitive to highly salt tolerant plants.

While most crops are generally susceptible to salt, a small percentage of wild species - the halophytes - are adapted to extremely saline natural habitats (Flowers and Colmer, 2008, 2015). This applies to trees as well, whereby fruit trees like avocado and citrus are sensitive even to salt 
concentrations at the low millimolar level (Zhu, 2007), while some deciduous tree species seem to be relatively tolerant to salt spraying and contact (Kayama et al., 2003; Goodrich et al., 2009).

The European larch (Larix decidua Mill.), a conifer present in the subalpine belt of Central Europe (Geburek, 2010), is an economically important timber species that is not commonly affected by soil salinity in its natural growing areas. This explains why studies on the mechanisms of response of this species to salt stress are scarce and, consequently, little is known about those mechanisms. However, larch trees are widely used in urban landscaping, where they can be affected by salt stress if irrigated with lowquality, reclaimed water. Even in the natural habitats of $L$. decidua, tree stands located in the proximity of mountain roads may suffer the effects of high soil salinity due to the common practice of winter de-icing with large amounts of $\mathrm{NaCl}$. Therefore, elucidating the mechanisms of salt stress responses in larch does not lack academic interest and may have practical relevance.

The major aim of the present study was to identify in European larch biochemical markers of salt stress associated to conserved defence mechanisms: control of ion transport, maintenance of cellular osmotic balance and synthesis of antioxidants, as it was previously done with Norway spruce (Schiop et al., 2015). In this regard, the levels of different compounds were determined in needles of salt-treated and control larch seedlings: photosynthetic pigments (chlorophylls $\mathrm{a}$ and $\mathrm{b}$, and total carotenoids), monovalent ions $\left(\mathrm{Na}^{+}, \mathrm{Cl}, \mathrm{K}^{+}\right)$, osmolytes (proline and total soluble sugars), malondialdehyde (MDA, an oxidative stress biomarker) and total phenolic compounds and flavonoids (as example of antioxidant metabolites). The experiments were performed with plant material derived from different natural larch provenances in Romania, in an attempt to identify populations with relatively higher salt tolerance, which could eventually be used in reforestation programmes. The same populations have been previously analysed from a genetic point of view, using genomic simple sequence repeat (SSR) markers (Gramazio et al., 2018).

\section{Materials and Methods}

\section{Growth conditions and experimental design}

Seeds were obtained from the seven Romanian larch populations described in Gramazio et al. (2018). Seeds were sown on a mixture of peat (50\%), perlite $(25 \%)$ and vermiculite $(25 \%)$, and grown in the glasshouses of the Institute for Plant Molecular and Cellular Biology (UPV), Valencia, Spain, under the following controlled conditions: long-day photoperiod ( $16 \mathrm{~h}$ of light), with light intensity of $130 \mu \mathrm{E} \mathrm{m}^{-2} \mathrm{~s}^{-1}$, temperature of $23^{\circ} \mathrm{C}$ during the day and 17 ${ }^{\circ} \mathrm{C}$ at night, and relative humidity ranging between 50 and $80 \%$. Hoagland's nutritive solution (Hoagland and Arnon, 1950) was administered twice a week for two months after seed germination. Salt stress was applied to these twomonth-old seedlings by watering the pots with $150 \mathrm{mM}$ $\mathrm{NaCl}$ solutions, twice a week for one month. In parallel, control plants were grown under the same conditions, but without any salt supplementation in the irrigation solution. Five biological replicates (five individual seedlings) were used per treatment and per provenance.

\section{Soil analysis}

Electrical conductivity $\left(\mathrm{EC}_{1: 5}\right)$ of the pot substrate, a parameter reflecting soil salinity level, was measured after the end of the applied treatment to validate the uniformity of the salt treatments applied to all studied populations. Soil samples (five per treatment, per provenance) were collected from each pot, air-dried and then passed through a 2 millimeter sieve. A suspension composed of soil:water (ratio 1:5) was prepared in deionised water and mixed by stirring for one hour at $600 \mathrm{rpm}$ at $21^{\circ} \mathrm{C}$, before being filtered. Electric conductivity was measured with a Crison 522 conductivity meter and expressed in $\mathrm{d} S \mathrm{~m}^{-1}$.

\section{Analysis of plant growth and dehydration of samples}

Seedlings were sampled after one month of salt treatment and the stem length and total weight of shoots were determined. Some of the harvested needles were weighed (fresh weight, FW), dried in an owen at $65^{\circ} \mathrm{C}$ for four days and then weighed again (dry weight, DW). Water content percentage (WC\%) of the needles was then calculated by the following formula:

$\mathrm{WC} \%=[(\mathrm{FW}-\mathrm{DW}) / \mathrm{FW}] \times 100$.

\section{Photosynthetic pigments measurements}

Photosynthetic pigments, including total carotenoids (Caro), chlorophyll a (Chl a) and chlorophyll b (Chl b), were quantified following the protocol established by Lichtenthaler and Welburn (1983). Fresh needles were ground and extracted in $80 \%$ ice-cold acetone. Absorbance was measured at $663 \mathrm{~nm}, 646 \mathrm{~nm}$, and $470 \mathrm{~nm}$. The concentration of each photosynthetic pigment was calculated according to the following equations, and then converted into $\mathrm{mg} \mathrm{g}^{-1} \mathrm{DW}$ :

- $\quad C h l a\left(\mu \mathrm{g} \mathrm{mL}^{-1}\right)=12.21 \times\left(\mathrm{A}_{663}\right)-2.81 \times\left(\mathrm{A}_{646}\right)$;

- $\quad$ Chl b $\left(\mu \mathrm{g} \mathrm{mL}^{-1}\right)=20.13 \times\left(\mathrm{A}_{646}\right)-5.03 \times\left(\mathrm{A}_{663}\right)$;

- $\operatorname{Caro}\left(\mu \mathrm{g} \mathrm{mL}^{-1}\right)=\left(1000 \times \mathrm{A}_{470}-3.27 \times[\mathrm{Chl} \mathrm{a}]-\right.$ $10 \times[\mathrm{Chl} \mathrm{b}]) / 229$

Table 1. Origin of seeds germinated to obtain the seedlings used in the greenhouse experiments

\begin{tabular}{|c|c|c|c|c|}
\hline Population & Provenance & Latitude & Longitude & Altitude (m.s.s) (m asl) \\
\hline 1 & Anina & $45^{\circ} 54^{\prime} \mathrm{N}$ & $21^{\circ} 51^{\prime} \mathrm{E}$ & $680-710$ \\
\hline 2 & Latorita & $45^{\circ} 23^{\prime} \mathrm{N}$ & $23^{\circ} 50^{\prime} \mathrm{E}$ & $1.000-1.200$ \\
\hline 3 & Gura Humorului & $47^{\circ} 33^{\prime} \mathrm{N}$ & $25^{\circ} 53^{\prime} \mathrm{E}$ & $520-570$ \\
\hline 4 & Brasov Valea Cetatii & $45^{\circ} 38^{\prime} \mathrm{N}$ & $25^{\circ} 36^{\prime} \mathrm{E}$ & 800 \\
\hline 5 & Sacele & $45^{\circ} 37^{\prime} \mathrm{N}$ & $25^{\circ} 41^{\prime} \mathrm{E}$ & $870-940$ \\
\hline 6 & Brasov Valea Popii & $45^{\circ} 25^{\prime} \mathrm{N}$ & $25^{\circ} 19^{\prime} \mathrm{E}$ & $670-700$ \\
\hline 7 & Sinaia & $45^{\circ} 19^{\prime} \mathrm{N}$ & $25^{\circ} 33^{\prime} \mathrm{E}$ & 750 \\
\hline
\end{tabular}


432

\section{Ion contents measurement}

Potassium $\left(\mathrm{K}^{+}\right)$, chloride $\left(\mathrm{Cl}^{-}\right)$and sodium $\left(\mathrm{Na}^{+}\right)$ contents were measured in needles sampled after one month of salt and control treatments, as described by Weimberg (1987). The extracts were prepared by incubating the samples (50 mg of finely ground, dry material suspended in $15 \mathrm{~mL}$ of water), for one $\mathrm{h}$ in a water bath at $95^{\circ} \mathrm{C}$, followed by filtration through a nylon filter of $0.45 \mu \mathrm{m}$ pore. A PFP7 flame photometer (Jenway Inc., Burlington, USA) was used to quantify the levels of $\mathrm{Na}^{+}$and $\mathrm{K}^{+}$cations, while $\mathrm{Cl}^{-}$ contents were measured with a chloride analyser.

\section{Osmolyte quantification}

Proline (Pro) content was measured in fresh tissue by the ninhydrin-acetic acid method of Bates et al. (1973). Briefly, needle extracts prepared in 3\% (w/v) sulfosalicylic acid solution were mixed with acid ninhydrin, incubated for one h at $95^{\circ} \mathrm{C}$ in a water bath, cooled and extracted with toluene. The absorbance of the organic phase was determined at $520 \mathrm{~nm}$, with toluene as a blank. Pro concentration was calculated in $\mu \mathrm{mol} \mathrm{g}{ }^{-1} \mathrm{DW}$.

Total soluble sugars (TSS) were quantified according to Dubois et al. (1956). Methanol (80\%,v/v) extracts of needle samples were mixed with $5 \%$ phenol, concentrated $\mathrm{H}_{2} \mathrm{SO}_{4}$ was added to the samples, which were rapidly mixed and incubated for $20 \mathrm{~min}$ at $30^{\circ} \mathrm{C}$, and finally, the absorbance at $490 \mathrm{~nm}$ was determined. Glucose was used to prepare the standard curve for the assay, and TSS contents were expressed as 'mg equivalent of glucose' per gram of DW.

\section{Malondialdebyde (MDA) and non-enzymatic antioxidants}

Methanol (80\% v/v) extracts were prepared from $50 \mathrm{mg}$ needles, by shaking in a rocker shaker at room temperature, for 24-48 h. Supernatants, collected by centrifugation, were stored in a freezer at $-20{ }^{\circ} \mathrm{C}$. MDA was quantified following the method described by Hodges et al. (1999). Samples were mixed with $0.5 \%$ thiobarbituric acid (TBA) prepared in $20 \%$ trichloroacetic acid (TCA) - or with $20 \%$ TCA without TBA for the controls - and then incubated at $95{ }^{\circ} \mathrm{C}$ for $20 \mathrm{~min}$. After cooling on ice and a centrifugation step, the absorbance of the supernatants was measured at $532 \mathrm{~nm}$. The non-specific absorbance at 600 and $440 \mathrm{~nm}$ was subtracted and the MDA concentration determined using the equations from Hodges et al. (1999).

Total phenolic compounds (TPC) were analysed by the method described in Blainski et al. (2013), based on the reaction with the Folin-Ciocalteu reagent. Samples were mixed with the reagent and sodium bicarbonate and left in the dark for $90 \mathrm{~min}$. The absorbance was recorded at 765 $\mathrm{nm}$, using gallic acid (GA) as the standard. TPC concentrations were expressed as GA equivalents (mg eq. $\mathrm{GA} \mathrm{g}^{-1} \mathrm{DW}$ ).

Total flavonoids (TF) were determined in the same extracts by the method described by Zhishen et al. (1999), based on the reaction of phenolic rings bearing a catechol group with $\mathrm{NaNO}_{2}$, followed by $\mathrm{AlCl}_{3}$ in the presence of $\mathrm{NaOH}$. The absorbance was read at $510 \mathrm{~nm}$ using catechin as the standard. TF concentration was expressed as equivalents of catechin (mg eq. $\mathrm{C} \mathrm{g}^{-1} \mathrm{DW}$ ).

\section{Statistical analysis}

Data were analysed using the programme Statgraphics Centurion v.16. Before the analysis of variance, the ShapiroWilk test was used to check for validity of normality assumption and Levene's test for the homogeneity of variance. If ANOVA requirements were accomplished, the significance of the differences among treatments was tested by one-way ANOVA at a 95\% confidence level, and post hoc comparisons were made using the Tukey HSD test. All means throughout the text are followed by SE.

\section{Results}

\section{Soil electric conductivity $\left(E C_{1: 5}\right)$}

Soil electric conductivity $\left(\mathrm{EC}_{1: 5}\right)$ reflects soil salinity, as it is closely correlated with the ionic contents of the pot substrates. A significant increase in soil $\mathrm{EC}_{1: 5}$ was observed in the pots watered with $150 \mathrm{mM} \mathrm{NaCl}$, as compared to the corresponding controls, for all studied larch populations (Fig. 1). The measured conductivities did not show any statistically significant inter-population differences in salt treated soils (Fig. 1). These data confirm that the salt stress treatment was applied uniformly to all seedlings of the different populations.

\section{Analysis of plant growth and dehydration of samples}

Stem length was measured at the end of the assays, after 30 days of treatments. In all analysed populations, mean values of salt-stressed seedlings were significant lower than those of the respective controls (Fig. 2A), with similar relative reductions of stem length in seedlings of all populations, except those from Sacele (Population 5), which showed the maximum difference, almost $40 \%$ of the control.

A salt-induced inhibition of biomass accumulation, reflected in the relative reduction of the control fresh weight, was also observed for the seven populations (Fig. 2B). The differences between salt-treated and control samples, however, were not significant in seedlings from Anina (Population 1) and Gura Humorului (Population 3). On the other hand, plants from Brasov Valea Popii (Population 6) and Sinaia (Population 7) appeared to be more affected by the $\mathrm{NaCl}$ treatments, as they showed more pronounced differences with the controls than the other populations (Fig. 2B).

Water loss is generally a physiological biomarker of high salinity in plants since leaf dehydration is a direct effect of the osmotic component of salt stress.

Water content percentage (WC\%) was determined in the harvested needles of the studied populations of Romanian larch (Fig. 2C). Control needles of all seven populations had similar WC\%, with small - though statistically significant - variations, ranging from 78 to $82 \%$. As expected, WC\% decreased in all samples in the presence of $150 \mathrm{mM} \mathrm{NaCl}$.

Salt-induced loss of needle water, however, was relatively small (although significant, except in seedlings from the Anina provenance), in no case higher than 5\% (Fig 2C). Therefore, under the conditions used in the experiments, larch seedlings appear to be relatively resistant to saltinduced dehydration. 


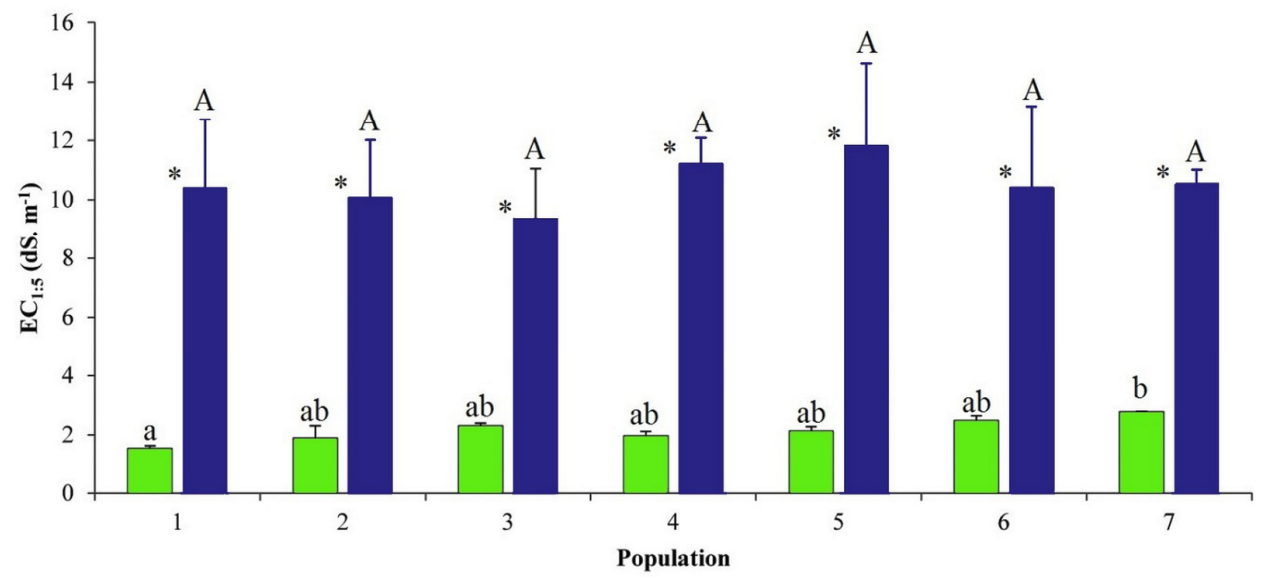

Treatments (mM NaCl):

$\square 0 \square 150$

Fig. 1. Soil electric conductivity $\left(\mathrm{EC}_{1: 5}\right)$ of the pot substrates, for the seven studied populations of Romanian larch, after 30 days of salt treatment. Values shown are means \pm SE $(n=5)$, expressed in $\mathrm{dS} \mathrm{m}^{-1}$. Different letters over the bars (lower case for controls and capital letters for salt-stressed plants) indicate significant differences between different populations according to Tukey test $(\alpha=0.05)$. Asterisks $\left(^{*}\right)$ indicate significant differences between salt and control treatments for the same population. Populations are given number codes according to Table 1
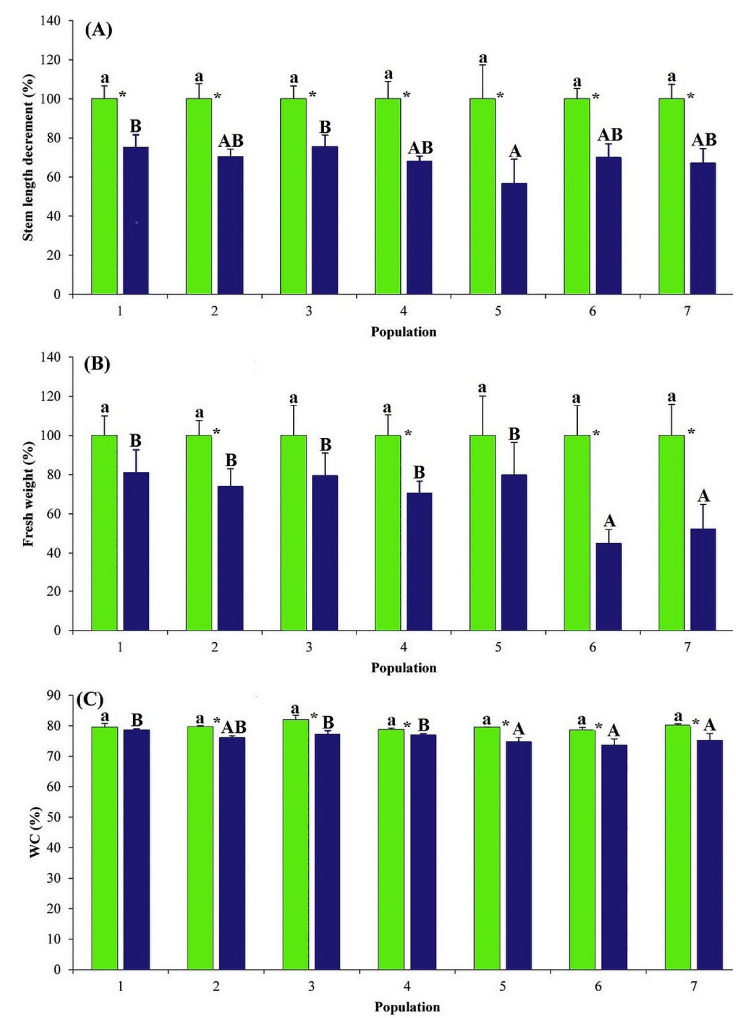

Treatments $(\mathrm{mM} \mathrm{NaCl})$ : $\square 0 \square 150$

Fig. 2. Stress-induced inhibition of growth in Larix decidua after 30 days of treatments $(150 \mathrm{mM} \mathrm{NaCl}$ and non-stressed controls). (A) Relative stem length reduction; (B) Relative fresh weight reduction; (C) Water content as a percentage of FW (WC\%). Values shown are means \pm SE $(n=5)$. Different letters (lower case for controls and capital letters for saltstressed plants) in a column indicate significant differences between different populations according to Tukey test $(\alpha=$ $0.05)$. Asterisks $\left({ }^{*}\right)$ indicate significant differences between salt-treated and control seedlings of the same population. Populations are given number codes according to Table 1 .

\section{Photosynthetic pigments}

Salt stress has many deleterious effects on the affected plants, including the oxidation and degradation of photosynthetic pigments; this causes a reduction in photosynthetic yield, which is one of the reasons for the saltinduced inhibition of plant growth. The contents of photosynthetic pigments were measured in the needles of control and salt-treated seedling of the seven studied larch populations (Fig. 3). In control, non-treated seedlings, Chl $\mathrm{a}, \mathrm{Chl} \mathrm{b}$ and Caro levels did not vary significantly when comparing the different larch populations, except for population 6 (Brasov Valea Popii), which showed lower contents of the three pigments. As expected, watering the plants for one month with $150 \mathrm{mM} \mathrm{NaCl}$ led to a reduction in the levels of the three measured photosynthetic pigments, in all seven larch populations; the salt-dependent reduction of chlorophylls ( $\mathrm{a}$ and b) contents was statistically significant in all cases (Fig. 3A, B), whereas total carotenoids showed a significant decrease only in populations 1 (Anina), 4 (Brasov Valea Cetatii ), 5 (Sacele ) and 6 (Brasov Valea Popii), but not in the other three (Fig. 3C). Some quantitative inter-population differences were observed, regarding the degree of pigment contents reduction, with populations 4 and 5 registering the most significant decrease, while population 7 recorded the smallest change with respect to its control levels.

\section{Ionic contents}

Ionic contents were measured in the needles of larch seedlings from the seven studied populations, showing a significant increase in $\mathrm{Na}^{+}$and $\mathrm{Cl}^{-}$ions in all salt-treated plants, in comparison with their respective controls (Table 2). Nonetheless, this relative increment varied widely, quantitatively, between the different populations. For example, $\mathrm{Na}^{+}$needle contents increased from about 2-fold in population 1 (Anina) to almost 7-fold in population 3 (Gura Humorului), with intermediate values for the other provenances. The relative increase of $\mathrm{Cl}^{-}$in needles of $\mathrm{NaCl}$ treated seedlings was more pronounced, ranging between 3.5 -fold in population 1 and more than 20-fold in population 7 (Sinaia) (Table 2). 
434
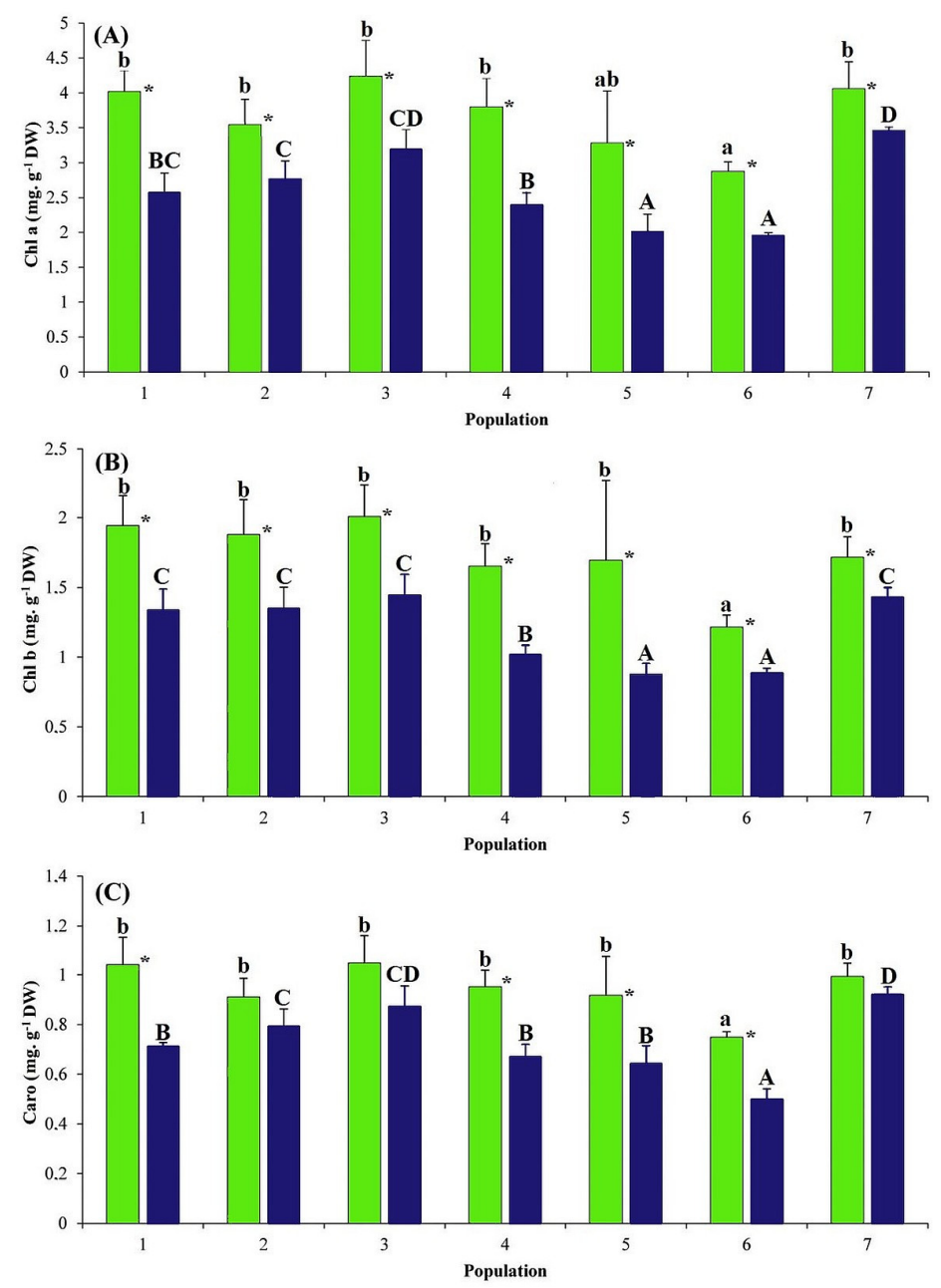

Treatments (mM NaCl):

$\square 0 \square 150$

Fig. 3. Photosynthetic pigments contents in seedling needles of the seven studied populations of Romanian larch, expressed in mg $\mathrm{g}^{-1}$ DW. (A) chlorophyll a ( $\mathrm{Chl} \mathrm{a);} \mathrm{(B)} \mathrm{chlorophyll} \mathrm{b} \mathrm{(} \mathrm{Chl} \mathrm{b);} \mathrm{(C)} \mathrm{carotenoids} \mathrm{(Caro).} \mathrm{Values} \mathrm{shown} \mathrm{are} \mathrm{means} \pm$ SE $(\mathrm{n}=5)$. Different letters over the bars (lower case for controls and capital letters for salt-stressed plants) indicate significant differences between different populations according to Tukey test $(\alpha=0.05)$. Asterisks $\left(^{*}\right)$ indicate significant differences between salttreated and control seedlings of the same population. Populations are given number codes according to Table 1

Table 2. Ion contents $\left(\mathrm{Na}^{+}, \mathrm{K}^{+}, \mathrm{Cl}\right)$ and $\mathrm{K}^{+} / \mathrm{Na}^{+}$ratios in seedling needles of the seven populations of Romanian larch. Values shown are means $\pm \mathrm{SE}$ $(n=5)$. Different letters (lower case for controls and capital letters for salt-stressed plants) in a column indicate significant differences between different populations according to Tukey test $(\alpha=0.05)$. Asterisks $\left(^{*}\right)$ indicate significant differences between salt-treated and control seedlings of the same population

\begin{tabular}{|c|c|c|c|c|c|c|c|c|}
\hline \multirow{3}{*}{ Population } & \multirow{2}{*}{\multicolumn{2}{|c|}{$\begin{array}{c}\mathrm{Na}^{+} \\
\left(\mu \mathrm{mol} \mathrm{g}^{-1} \mathrm{DW}\right) \\
\begin{array}{c}\mathrm{NaCl} \text { treatment } \\
(\mathrm{mM})\end{array}\end{array}$}} & \multirow{2}{*}{\multicolumn{2}{|c|}{$\begin{array}{c}\mathrm{K}^{+} \\
\left(\mu \mathrm{mol} \mathrm{g}^{-1} \mathrm{DW}\right) \\
\begin{array}{c}\mathrm{NaCl} \text { treatment } \\
(\mathrm{mM})\end{array}\end{array}$}} & \multirow{2}{*}{\multicolumn{2}{|c|}{$\begin{array}{c}\mathrm{Cl}^{-} \\
\left(\mu \mathrm{mol} \mathrm{g}^{-1} \mathrm{DW}\right) \\
\begin{array}{c}\mathrm{NaCl} \text { treatment } \\
(\mathrm{mM})\end{array}\end{array}$}} & \multicolumn{2}{|c|}{$\mathrm{K}^{+} / \mathrm{Na}^{+}$} \\
\hline & & & & & & & & \\
\hline & 0 & 150 & 0 & 150 & 0 & 150 & 0 & 150 \\
\hline 1 & $212.5 \pm 3.7 \mathrm{c}^{*}$ & $414.7 \pm 59.6 \mathrm{~A}^{*}$ & $438.4 \pm 13.6 b^{*}$ & $566.2 \pm 71.4 C^{*}$ & $193.8 \pm 8.3 \mathrm{c}^{*}$ & $706.6 \pm 78.2 \mathrm{~A}^{*}$ & 2.06 & 1.36 \\
\hline 2 & $173.6 \pm 11.4 \mathrm{~b}^{*}$ & $564.1 \pm 116.1 \mathrm{~B}^{*}$ & $431.3 \pm 25.1 \mathrm{~b}$ & $466.9 \pm 19.9 \mathrm{~B}$ & $83.7 \pm 9.5 \mathrm{ab}^{*}$ & $750.5 \pm 173.9 \mathrm{~A}^{*}$ & 2.48 & 0.82 \\
\hline 3 & $123.7 \pm 5.8 \mathrm{a}^{*}$ & $836.7 \pm 96.6 \mathrm{C}^{*}$ & $368.4 \pm 15.9 \mathrm{a}^{*}$ & $466.4 \pm 32.8 \mathrm{~B}^{*}$ & $102.8 \pm 16.5 b^{*}$ & $740.5 \pm 111.8 \mathrm{~A}^{*}$ & 2.97 & 0.55 \\
\hline 4 & $156.0 \pm 10.4 \mathrm{~b}^{*}$ & $651.6 \pm 54.2 \mathrm{~B}^{*}$ & $427.8 \pm 26.9 b$ & $493.4 \pm 26.7 \mathrm{~B}$ & $103.6 \pm 8.7 \mathrm{~b}^{*}$ & $938.2 \pm 31.6 \mathrm{~B}^{*}$ & 2.74 & 0.75 \\
\hline 5 & $161.3 \pm 25.1 b^{*}$ & $724.2 \pm 188.4 \mathrm{BC}^{*}$ & $393.4 \pm 45.6 \mathrm{ab}$ & $419.1 \pm 9.4 \mathrm{~A}$ & $71.0 \pm 28.2 \mathrm{a}^{*}$ & $798.1 \pm 241.18 \mathrm{~A}^{*}$ & 2.43 & 0.57 \\
\hline 6 & $174.1 \pm 7.0 \mathrm{~b}^{*}$ & $944.9 \pm 48.7 \mathrm{C}^{*}$ & $358.8 \pm 43.6 \mathrm{a}$ & $417.6 \pm 19.5 \mathrm{~A}$ & $64.3 \pm 0.7 a^{*}$ & $1008.1 \pm 213.6 B^{*}$ & 2.06 & 0.44 \\
\hline 7 & $212.3 \pm 11.8 \mathrm{c}^{*}$ & $1080.2 \pm 47.8 \mathrm{D}^{*}$ & $447.2 \pm 11.1 \mathrm{~b}^{*}$ & $549.3 \pm 27.7 \mathrm{C}^{*}$ & $63.5 \pm 17.3 \mathrm{a}^{*}$ & $1295.8 \pm 64.8 \mathrm{C}^{*}$ & 2.11 & 0.51 \\
\hline
\end{tabular}


Accumulation of $\mathrm{Na}^{+}$in the leaves is normally accompanied by a reduction of $\mathrm{K}^{+}$contents, as both cations compete for the same transport systems. Larch, however, appears to possess efficient mechanisms to maintain $\mathrm{K}^{+}$ concentrations under salt stress, as its levels in needles did only not decrease in the salt-treated plants, but rather increased in all tested populations - even if only slightly and, in several cases, not significantly (Table 2). The combination of these salt-induced changes in $\mathrm{Na}^{+}$and $\mathrm{K}^{+}$ levels led to a reduction in $\mathrm{K}^{+} / \mathrm{Na}^{+}$ratios, down to $20-30 \%$ of the non-stressed control values in all populations, except for provenance 1 - ca. $70 \%$ of the control (Table 2).

\section{Osmolytes quantification}

Stressed plants ubiquitously produce osmolytes to adjust their osmotic potential. Thus, the levels of two common plant osmolytes were measured in the needles of the studied larch plants. Proline (Pro) showed a significant increase in salt-stressed seedlings of the seven analysed populations, varying from 4- to 7-fold over the control values determined in non-stressed plants (Fig. 4A). Absolute Pro concentrations reached values of $30-40 \mu \mathrm{mol} \mathrm{g} \mathrm{g}^{-1} \mathrm{DW}$, which, assuming the accumulation of the osmolyte predominantly in the cell cytoplasm, would contribute to osmotic adjustment under salt stress.

Total soluble sugars (TSS) were also quantified in the larch seedlings (Fig. 4B).
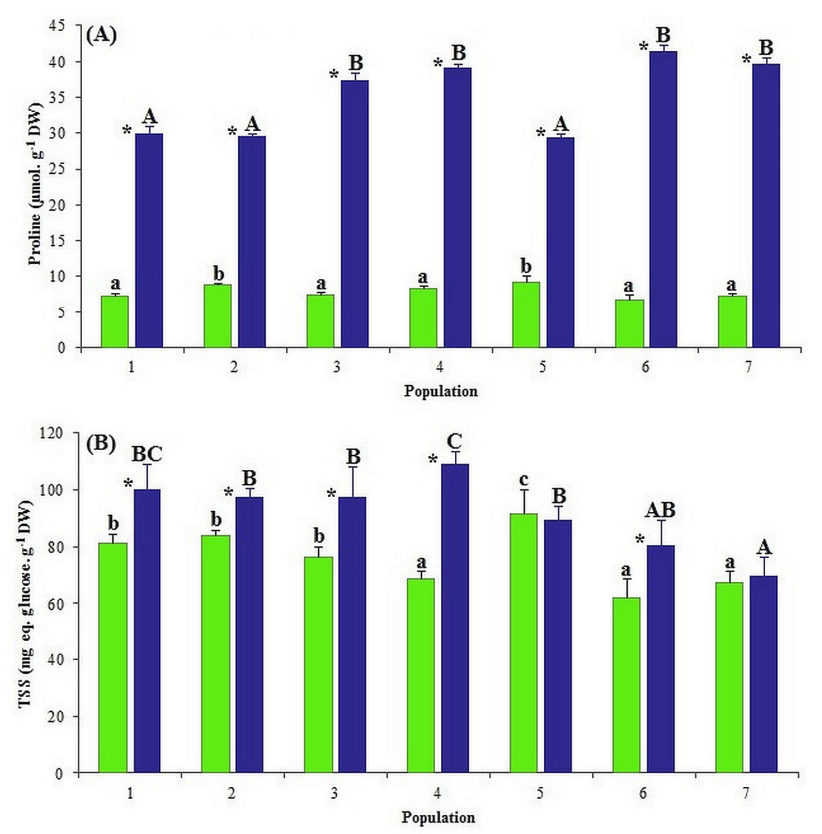

Treatments (mM NaCl):

$\square 0 \square 150$

Fig. 4. Measured osmolytes of the seven studied populations of Romanian larch. (A) Proline (Pro) contents expressed in $\mu \mathrm{mol}$ $\mathrm{g}^{-1}$ DW; (B) Total Soluble Sugars (TSS) contents expressed as mg eq. of glucose $\mathrm{g}^{-1} \mathrm{DW}$. Values shown are means $\pm \mathrm{SE}(\mathrm{n}=$ 5). Different letters over the bars (lower case for controls and capital letters for salt stressed plants) indicate significant differences between different populations according to Tukey test $(\alpha=0.05)$. Asterisks $\left({ }^{*}\right)$ indicate significant differences between salt-treated and control seedlings of the same population. Populations are given number codes according to Table 1.
TSS contents also increased significantly in response to the $\mathrm{NaCl}$ treatment, except in populations 5 and 7 , although the changes recorded were much smaller than those observed for Pro in the same samples (Fig. 4B).

\section{Malondialdehyde (MDA) and non-enzymatic antioxidants}

MDA is considered as an excellent indicator of oxidative stress (Del Rio et al., 2005) as increased levels indicate membrane degradation due to ROS accumulation. MDA contents increased significantly with respect to the corresponding controls, in needles of salt-treated seedlings from the seven larch populations analysed (Fig. 5A). The relative increment in MDA level varied slightly between provenances, but the absolute MDA concentration reached in the presence of salt was the same in all of them (Fig. 5A).

Contrary to MDA, Total Phenolic Compounds (TPC) needle contents decreased in response to salt, even though the changes with respect to the corresponding controls were generally non-significant or very small (Fig. 5B).
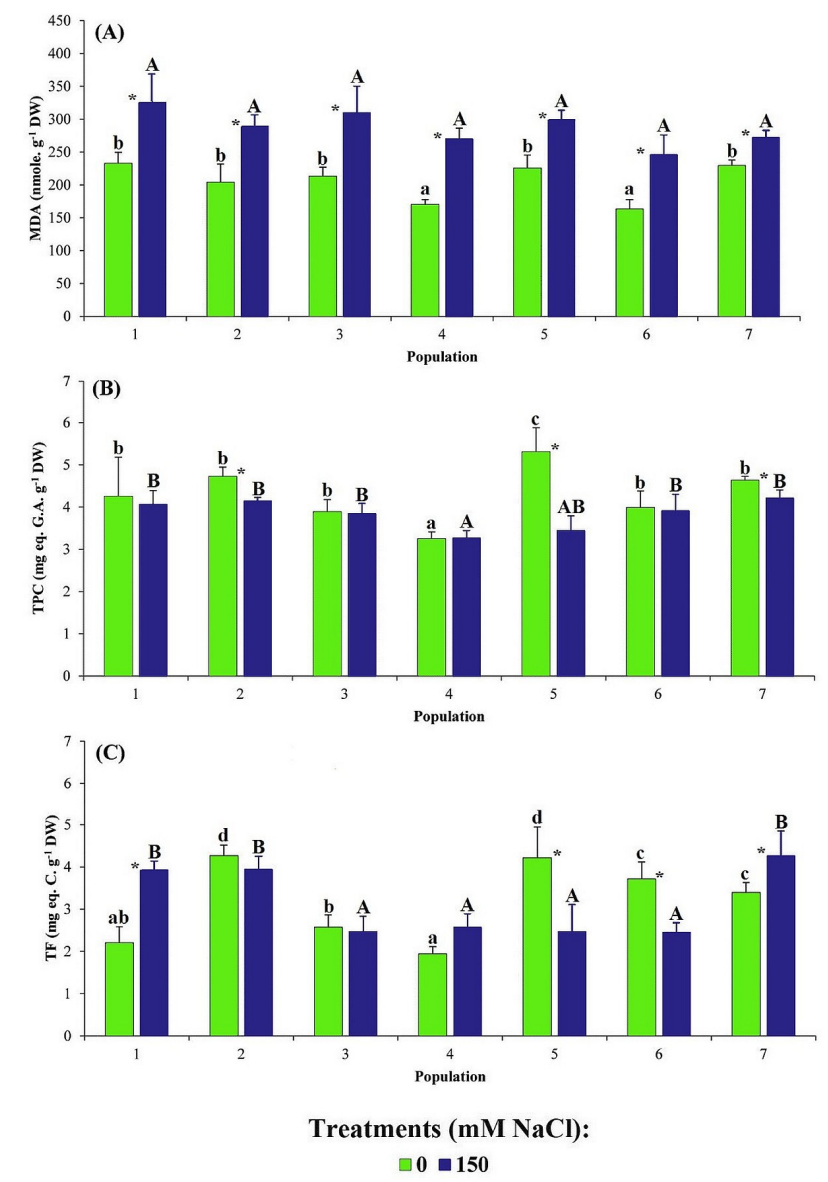

Fig. 5. Oxidative stress and antioxidant responses in the seven studied populations of Romanian larch. (A) Malondialdehyde (MDA) contents expressed in nmol g-1 DW; (B) Total Phenolic Compounds (TFC) expressed as mg eq. of gallic acid $\mathrm{g}^{-1} \mathrm{DW}$; (C) Total Flavonoids (TF) expressed as mg. eq. of cathechin $\mathrm{g}^{-1} \mathrm{DW}$. Values shown are means \pm SE $(n=5)$. Different letters over the bars (lower case for controls and capital letters for salt stressed plants) indicate significant differences between different populations according to Tukey test $(\alpha$ $=0.05)$. Asterisks $\left({ }^{*}\right)$ indicate significant differences between salttreated and control seedlings of the same population. Populations are given number codes according to Table 1. 
436

Total Flavonoids (TF) needle contents, on the other hand, did not show any clear pattern of variation in the saltstressed plants: significant increases, significant reductions and no significant changes in TF concentration were observed in the different larch populations (Fig. 5C).

\section{Discussion}

Growth inhibition is the first and most general reaction of plants to stress, as all resources are redirected from primary metabolism and biomass accumulation to the activation of defence reactions against stress (Zhu, 2001). Therefore, deleterious effects of stress are usually assessed in terms of growth reduction, by determining different growth parameters, such as stem length, foliar area, fresh weight or dry weight, etc. (e.g., Al Hassan et al., 2016a, b; Kumar et al., 2017). However, such indicators of stress based exclusively on growth parameters are not sufficient in the case of slowgrowing species, such as many woody species including conifers. In such species, the use of biochemical stress markers represents a rapid and reliable alternative for the detection of early effects of environmental stress, as it has been recently proposed in spruce (Schiop et al., 2015, 2017). All plants activate a series of basic, conserved mechanisms as a response to environmental stress and several metabolites involved in these responses - mono and divalent cations, osmolytes, photosynthetic pigments, antioxidant compounds, etc. - can be used, a priori, as stress biomarkers. However, the significance of these responses in the mechanisms of stress tolerance largely varies among taxa. The analysis of stress responses in species of the same genus (Cicevan et al., 2015; Al Hassan et al., 2016a,b; Koźmińska et al., 2018, 2019) or in different cultivars of the same species (Al Hassan et al., 2016c) allowed us to establish which of those responses were relevant for tolerance, through the identification of suitable biochemical markers for each investigated species or group of related taxa.

Except for the authors' previous study (Plesa et al., 2018), there are no other published reports dealing with the responses of Larix deciua to salt stress, and only a few on other species of this genus (e.g. Renault et al., 2005).

Among coniferous species, the European larch is considered as a relatively fast-growing tree (Matras and Paque, 2008). This was confirmed by the present experimental approach, since after one month of treatment a reduction of growth could be measured in salt-stressed plants as compared to their respective controls. The relative reduction of fresh weight was mostly due to growth inhibition and not to dehydration, as the water loss in needles from all populations was less than 5\%. Therefore, exposure of young seedlings to $150 \mathrm{mM} \mathrm{NaCl}$ has a deleterious effect on growth. There were some variations among the analysed populations, but they could not clearly separate populations that responded better to salinity.

Growth inhibition was associated with a reduction in the leaf contents of photosynthetic pigments. This reduction occurs in many plant species under diverse abiotic stresses, as the result of a combination of factors, such as the inhibition of chlorophyll biosynthesis, the activation of its degradation by chlorophyllase, and the inactivation of primary enzymes involved in photosynthesis (Santos, 2004). The reduction of photosynthetic pigments concentration under salt stress has been previously reported in larch (Plesa et al., 2018) and in other conifer species (Crosser, 2001; Schiop et al., 2015).

Potassium is considered as the 'physiological' cation, essential for plant growth and development, whose deficiency has negative effects on photosynthesis, osmoregulation, protein biosynthesis and other fundamental processes (Gierth and Mäser, 2007). On the contrary, high concentrations of sodium have negative effects in many physiological processes, by inhibiting enzymatic activities and interfering with $\mathrm{K}^{+}$uptake and homeostasis systems (Adams and Shin, 2014; RodriguezNavarro and Rubio, 2006). Glycophytes generally respond to high soil salinity by limiting the uptake of toxic ions, $\mathrm{Na}^{+}$ and $\mathrm{Cl}^{-}$, either by exclusion at the root level or by blocking their transport to the leaves (Munns et al., 2015; Mbarki et al., 2018). Several studies in Larix laricina (Renault, 2005), in Picea abies (Schiop et al., 2015) and recently in Larix decidua (Plesa et al., 2018) reported the maintenance of relatively high $\mathrm{K}^{+}$concentrations in the needles under saline conditions, as a mechanism to partly counteract the deleterious effects of salt stress. This pattern, which seems to be common in conifers, is rather unusual, as $\mathrm{Na}^{+}$ accumulation is generally accompanied by a reduction of $\mathrm{K}^{+}$ levels, as the two ions compete for the same transport systems (Greenway and Munns, 1980). Avoiding an excessive reduction of cytoplasmic $\mathrm{K}^{+} / \mathrm{Na}^{+}$ratios appears to be an important mechanism of defence against high salinity in European larch, as in all populations salt-stressed plants maintained or even increased slightly the needle $\mathrm{K}^{+}$ concentrations measured in control seedlings.

Another general mechanism of response to all types of environmental conditions, inducing osmotic stress, is the synthesis of compatible solutes or osmolytes, which are diverse compounds that do not interfere with cellular metabolism, even at high concentrations and help to avoid cell dehydration and to maintain osmotic balance under stress (Zhu, 2016). Proline is a common compatible solute in plants (Verbruggen and Hermans, 2008; Szabados and Savouré, 2010) and it has been reported to significantly increase in many plant species, both halophytes and glycophytes, in response to salt treatments. An increase in Pro has been described in many conifer species under salinity and/or drought conditions, for example, in pine (Newton et al., 1986; Zamani et al., 2014; Taibi et al., 2017) and spruce (Ditmarová et al., 2010; Schiop et al., 2015, 2017). In larch, a significant increase in Pro over control values was shown in the presence of cadmium, and were reported in the hybrid L. $\times$ eurolepis Henry (L. decidua $\times L$. kaempferi) and in L. decidua under saline stress (Bonet et al., 2016). In the present study, Pro values in the presence of salt varied in similar ranges in the seven larch populations, from 4- to 7-fold higher concentrations than in the corresponding controls. In addition to its possible contribution to cellular osmotic adjustment, Pro accumulation may have a significant role in the mechanisms of stress tolerance as a low-molecular-weight chaperon, ROS scavenger, or as a signalling molecule (Szabadosz and Savouré, 2010).

Soluble sugars also belong to the category of osmolytes in many plant species, including conifers (Clancy et al., 1995), but do not appear to play this functional role in European larch. A significant increase in TSS contents was observed in 
the stressed plants, but only in five of the seven populations analysed, not in all. Also, this variation was too small to consider that they may play an important osmoregulatory function in this species. In any case, it is always difficult to demonstrate the specific contribution of soluble sugars, acting as osmolytes, to the responses to stress, due to their multiple functional roles in plants, as metabolic precursors, energy sources, or signalling molecules.

MDA is a reactive aldehyde generated by the ROSinduced oxidation of membrane lipids and is used as a suitable biomarker of cellular oxidative stress (Del Rio et al., 2005). In the seven populations analysed, measured MDA concentrations were significantly higher in the seedlings exposed to salt stress than in the non-stressed controls, although this increment is smaller than that observed in other glycophytes under similar conditions (Al Hassan et al., 2017; Kumar et al., 2017; Nxele et al., 2017). In the present study, a clear pattern of variation in the concentrations of non-enzymatic antioxidants was not detected among the studied populations; when differences between the values registered in control and salt-stressed seedlings were observed, they were generally very low. These data are in agreement of those from our previous work (Plesa $\mathrm{et}$ al., 2018), which suggested that one month of exposure to 150 $\mathrm{mm} \mathrm{NaCl}$, generated only a weak oxidative stress in larch seedlings, due to the efficiency of the antioxidant enzymatic systems activated in response to the salt treatment. These antioxidant enzymes have been defined as the first line of defense against oxidative stress (Fini et al., 2011).

\section{Conclusions}

The detected biochemical responses to salt stress were similar in the seven Romanian populations of Larix decidua analysed in the present work. Several biochemical markers could be associated, for all populations, with the observed salt-induced inhibition of growth: decreasing levels of photosynthetic pigments, increasing concentrations of $\mathrm{Na}^{+}$ and $\mathrm{Cl}^{-}$, maintenance of $\mathrm{K}^{+}$levels, Pro and MDA accumulation in needles of European larch seedlings subjected to salt stress treatments. These parameters could be optimal for the rapid analysis of the degree of stress affecting the plants, at least at the seedling stage; further studies will be required to establish if these results can be extended to other developmental phases. The selected biochemical stress markers can be easily and rapidly quantified by non-destructive assays, requiring simple equipment and small amounts of plant material. Despite some quantitative variations in the responses of the different Romanian larch populations, it was not possible to identify any of them showing a higher degree of tolerance to salinity. The genetic analysis using SSR markers of the same populations revealed a large genetic diversity of highly heterozygous individuals, as well as limited genetic differentiation of those populations. Therefore, it was not likely that the studied populations could be differentiated by their biochemical responses to salt, as shown by the present results.

\section{References}

Adams E, Shin R(2014). Transport, signaling, and homeostasis of potassium and sodium in plants. Journal of Integrative Plant Biology 56:231-249.

Al Hassan M, Chaura J, Donat-Torres M, Boscaiu M, Vicente O (2017). Antioxidant responses under salinity and drought in three closely related wild monocots with different ecological optima. AoB Plants 9 plx009.

Al Hassan M, López-Gresa MP, Boscaiu M, Vicente O (2016 a). Stress tolerance mechanisms in Juncus: Responses to salinity and drought in three Juncus species adapted to different natural environments. Functional Plant Biology 43:949-960.

Al Hassan M, Morosan M, López-Gresa MP, Prohens J, Vicente O, Boscaiu M (2016 c). Salinity-induced variation in biochemical markers provides insight into the mechanisms of salt tolerance in common (Phaseolus vulgaris) and runner (P. coccineus) beans. International Journal of MolecularScience 17:1582.

Al Hassan M, Pacurar A, López-Gresa MP, Donat-Torres MP, Llinares JV, Boscaiu M, Vicente O (2016b). Effects of salt stress on three ecologically distinct Plantago species. PLoS One 11(8):e0160236.

Apel K, Hirt H(2004). Reactive oxygen species: metabolism, oxidative stress, and signal transduction. Annual Review of Plant Biology 55:373-399.

Bartels D, Sunkar R (2005). Drought and salt tolerance in plants. Critical Reviews in Plant Sciences 24:23-58.

Bates LS, Waldren RP, Teare LD (1973). Rapid determination of free proline for water-stress studies. Plant and Soil 39:205-207.

Blainski A, Lopes GC, Palazzodemello JC (2013). Application and analysis of the Folin Ciocalteu method for the determination of the total phenolic content from Limonium brasiliense L. Molecules 18:68526865.

Bonet A, Lelu-Walter MA, Faugeron C, Gloaguen V, Saladin G (2016). Physiological responses of the hybrid larch (Larix $\times$ eurolepis Henry) to cadmium exposure and distribution of cadmium in plantlets. Environmental Science and Pollution Research International 23:86178626.

BoyerJS (1982). Plant productivity and environment. Science 218:443-448.

Cicevan R, Al Hassan M, Sestras AF, Prohens J, Vicente O, Sestras RE, Boscaiu M (2016). Screening for drought tolerance in cultivars of the ornamental genus Tagetes (Asteraceae) PeerJ 4:e2133.

Clancy KM, Wagner MR, Reich PB (1995). Ecophysiology and insect herbivory. In: Smith WK, Hinckley TM (Eds). Ecophysiology of coniferous forests. Academic Press, San Diego, CA, USA pp 125-180.

Croser C, Renault S, Franklin J, Zwiazek J (2001). The effect of salinity on the emergence and seedling growth of Picea mariana, Picea glauca and Pinus banksiana. Environmental Pollution 115:9-16.

Del Rio D, Stewart AJ, Pellegrini N (2005). A review of recent studies on malondialdehyde as toxic molecule and biological marker of oxidative stress. Nutritional, Metabolic and Cardiovascular Diseases 15:316-328.

Ditmarová L, Kurjak D, Palmroth S, Kmet J, Strelcová K (2010). Physiological responses of Norway spruce (Picea abies) seedlings to drought stress. Tree Physiology 30:205-213.

Dubois M, Gilles KA, Hamilton JK, Reberd PA, Smith F (1956). Colorimetric method for determination of sugars and related substances. Analytical Chemistry 28:350-356.

Fini A, Brunetti C, Di Ferdinando M, Ferrini F, Tattini M (2011). Stressinduced flavonoid biosynthesis and the antioxidant machinery of plants. PlantSignaling and Behavior 6:709-711.

Flowers TJ, Colmer TD (2015). Plant salt tolerance: adaptations in halophytes. Annals of Botany 115:327-331.

Flowers TJ, Colmer TD (2008). Salinity tolerance in halophytes. New Phytologist 179:945-963.

Geburek T (2010).Larix decidua Miller, 1768. In: RoloffA, Weissgerber H, Lang U, Stimm B (Eds). Bäume Mitteleuropas Wiley, Weinheim, Germanypp 431-450.

Gierth M, Mäser P (2007). Potassium transporters in plants-Involvement in 
438

$\mathrm{K}^{+}$acquisition, redistribution and homeostasis. FEBS Letters 581:23482356.

Goodrich BA, Koski RD, Jacobi WR (2009). Condition of soils and vegetation along roads treated with magnesium chloride for dust suppression. Water, Air and Soil Pollution 198:165-188.

Gramazio P, Plesa IM, Truta AM, Sestras AF, Vilanova S, Plazas M, Vicente O, Boscaiu M, Prohens J, Sestras RE (2018). Highly informative SSR genotyping reveals large genetic diversity and limited differentiation in European larch (Larix decidua) populations from Romania. Turkish Journal of Agriculture and Forestry 42:165-175.

Greenway H, Munns R (1980). Mechanisms of salt tolerance in nonhalophytes. Annual Review of Plant Biology 31:149-190.

Hoagland DR, Arnon DI (1950). The water-culture method for growing plants without soil. California Agricultural Experiment Station Publications Series, College of Agriculture, University of California Davis, CA, USA.

Hodges DM, Delong JM, Forney CF, Prange RK (1999). Improving the thiobarbituric acid-reactive-substances assay for estimating lipid peroxidation in plant tissues containing anthocyanin and other interfering compounds. Planta 207:604611.

Kayama M, Quoreshi AM, KitaokaS, Kitahashi Y, Sakamoto Y, Maruyama Y, Kitao M, Koike T (2003). Effects of deicing salt on the vitality and health of two spruce species, Picea abies Karst, and Picea glehnii Masters planted along roadsides in northern Japan. Environmental Pollution 124:127-137.

Koskela J, Buck A, du Cros ET (2007).EUFORGEN Climate change and forest genetic diversity: Implications for sustainable forest management in Europe; Biodiversity International 2007. Retrieved 2017 November 15, from http://www.euforgen.org/fileadmin/ bioversity/publications/ $\mathrm{pdfs} / 1216$.

Koźmińska A, Al Hassan M, Hanus-Fajerska E, Naranjo MA, Boscaiu M, Vicente O (2018). Comparative analysis of water deficit and salt tolerance mechanisms in Silene. South African Journal of Botany 117:193-206.

Koźmińska A, Al Hassan M, Wiszniewska A, Hanus-FajerskaE, Boscaiu M, Vicente $O$ (2019). Response of succulents to drought: Comparative analysis of four Sedum (Crassulaceae) species. Scientia Horticulturae 243:235-242.

Kumar D, Al Hassan M, Naranjo MA, Agrawal V, Boscaiu M, Vicente O (2017). Effects of salinity and drought on growth, ionic relations, compatible solutes and activation of antioxidant systems in oleander (Nerium oleander L.).PLoSOne 12(9):e0185017.

Lichtenthaler HK, Wellburn AR (1983). Determinations of total carotenoids and chlorophylls a and b of leaf extracts in different solvents. Biochemical Society Transactions 11:591-592.

Lindner M, Maroschek M, Netherer S, Kremer A, Barbati A, GarciaGonzalo J, Lexer MJ (2010). Climate change impacts, adaptive capacity, and vulnerability of European forest ecosystems. Forest Ecology and Management 259:698-709.

Matras J, Pâques L (2008). EUFORGEN Technical guidelines for genetic conservation and use for European Larch (Larix decidua). Biodiversity International, Rome, Italy.

Mbarki S, Sytar O, Cerda A, Zivcak M, Rastogi A, He X, Zoghlami A, Abdelly C, Brestic M (2018). Strategies to mitigate the salt stress effects on photosynthetic apparatus and productivity of crop plants. In: Kumar V, Wani SH, Suprasanna P, Trann LSP (Eds). Salinity responses and tolerance in plants, Volume 1. Targeting Sensory, Signaling Mechanisms. Springer International Publishing AG, Cham, Switzerland pp 85-136.

Munns R, Tester M (2008). Mechanisms of salinity tolerance. Annual Reviewsin Plant Biology 59:651-681.

Newton RJ, Sen S, PuryearJD (1986). Free proline changes in Pinustaeda L. callusin response to drought stress. Tree Physiology 1:325-332.

Nxele X, Klein A, Ndimba BK (2017). Drought and salinity stress alters ROS accumulation, water retention, and osmolyte content in sorghum plants. South African Journal of Botany 108:261-266.

Plesa IM, González-Orenga S, Al Hassan M, Sestras AF, Vicente O, Prohens J, Sestras RE, Boscaiu M (2018). Effects of drought and salinity on European Larch (Larix decidua Mill.) seedlings. Forests 9:320.

Renault S (2005). Tamarack response to salinity: Effects of sodium chloride on growth and ion, pigment, and soluble carbohydrate levels. Canadian Journal of Forest Research 35:2806-2812.

Rodriguez-Navarro A, Rubio F (2006). High-affinity potassium and sodium transport systems in plants. Journal of Experimental Botany 57:11491160.

Santos CV (2004). Regulation of chlorophyll biosynthesis and degradation by salt stress in sunflower leaves. Scientia Horticulturae 103:93-99.

Shiop ST, Al Hassan M, Sestras AF, Boscaiu M, Sestras RE, Vicente O (2015). Identification of salt stress biomarkers in Romanian Carpathian populations of Picea abies (L.) Karst. PLoS One 10:e0135419.

Schiop ST, Al Hassan M, Sestras AF, Boscaiu M, Sestras RE, Vicente O (2017). Biochemical responses to drought, at the seedling stage, of several Romanian Carpathian populations of Norway spruce (Picea abies (L.) Karst). Trees 31:1479-1490.

Szabados L, Savouré A (2010). Proline: A multifunctional aminoacid. Trendsin Plant Science 15:89-97.

Täbi K, del Campo AD, Vilagrosa A, Bellés JM, López-Gresa MP, Pla D, Calvete J, López-Nicolás JM, Mulet JM (2017). Drought tolerance in Pinus halepensis seed sources as identified by distinctive physiological and molecular markers. Frontiers in Plant Science 8,202.

Várallyay $G(2010)$. The impact of climate change on soils and on their water management. Agronomy Research 8:385-396.

Verbruggen N, Hermans C (2008). Proline accumulation in plants: A review. Amino Acids 35:753-759.

Weimberg R (1987). Solute adjustments in leaves of two species of wheat at two different stages of growth in response to salinity. Physiologia Plantarum 70:381-388.

Zamani M, Hakimi MH, Mosleh Arany A, Kiani B, Rashtian A (2014). Comparing the effects of SNP and SA under salinity stress on proline, sugar, Na, K and chlorophyll of leaves of Pinus eldarica and Cupressus sempervirens in Iran. Bulletin of Environment Pharmacology and Life Sciences 3:91-95.

Zhishen J, Mengcheng T, Jianming W (1999). The determination of flavonoid contents in mulberry and their scavenging effects on superoxide radicals. Food Chemistry 64:555-559.

ZhuJK (2001).Plant salt tolerance. Trendsin Plant Science 6:66-71.

ZhuJK(2007).Plant salt stress. Encyclopaedia of Life Sciences. In: eLS.John Wiley \& Sons Ltd, Chichester. http://www.els.net [doi: 10.1002/9780470015902.a0001300.pub2].

Zhu JK (2016). Abiotic stress signalling and responses in plants. Cell 167:313-324. 